\title{
RENDAM KAKI DENGAN AIR HANGAT SALAH SATU TERAPI YANG MAMPU MENGATASI INSOMNIA PADA LANSIA
}

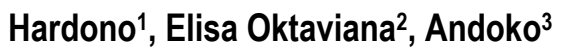

1Program Studi IImu Keperawatan STIKes Aisyah Pringsewu, Lampung. Email: hardonoaisyah2009@gmail.com 2Program Studi S1 IImu Keperawatan STIKes Yarsi Mataram, NTB. Email: oktavianaelisa194@gmail.com 3Program Studi IImu Keperawatan, Universitas Malahayati, Bandar Lampung. Email: andoko2013@gmail.com

\section{ABSTRACT : THE EFFECTS OF WARM-WATER FOOTBATH ON INSOMNIA AMONG ELDERLY}

Background: Insomnia is often considered normal when it is allowed to cause disease and even death, especially in the elderly with a percentage of $50 \%$ of elderly experiencing insomnia. At the Tresna Werdha Social Home of 10 elderly, there were about 4 elderly who had experienced on mild to severe insomnia.

Purpose: This study was to determine the effect of warm-water footbath on insomnia among elderly at the Tresna Werdha Natar Social Home.

Methods: The design of the study used a quasi-experimental with the one group pretest-posttest design method. The population of this study was 17 elderly who were experiencing a mild and severe insomnia with a sampling technique by total sampling.

Results : Statistical tests using paired $t$ test. Clinical results obtained a mean score before 25.76 meaning mild insomnia and an average score after 17.18 means with a decrease of 8,588. The statistical test results obtained a significant value of 0.000 ( $p$-Value $<0.05$ ) which means Ha is accepted

Conclusion: There is the effect of of warm-water footbath on insomnia among elderly. It is recommended that this study can be a safe therapy for the elderly who has suffered on insomnia, especially in nursing homes.

\section{Keywords: Warm-water footbath, insomnia, elderly}

Pendahuluan : Insomnia sering dianggap hal yang biasa padahal bila dibiarkan dapat menimbulkan penyakit bahkan kematian terutama pada lansia dengan persentasi 50\% lansia mengalami insomnia. Di Panti Sosial Tresna Werdha dari 10 lansia terdapat 4 lansia yang mengalami insomnia di usia 65 tahun sampai 74 tahun dari insomnia ringan sampai berat.

Tujuan : penelitian ini untuk mengetahui pengaruh rendam kaki dengan air hangat terhadap penurunan insomnia lansia di Panti Sosial Tresna Werdha Natar.

Metode : Desain penelitian menggunakan quasi eksperimen dengan metode pendekatan one group pretest-posttest design. Populasi penelitian ini adalah 17 lansia yang mengalami insomnia ringan dan berat dengan teknik pengambilan sampel dengan cara total sampling

Hasil : Uji statistik menggunakan paired t test.Hasil klinis didapat skor rerata sebelum 25.76 artinya insomnia ringan dan skor rerata sesudah 17.18 artinya tidak insomnia dengan penurunan 8.588. Hasil uji statistik didapat nilai signifikan $0.000(P$-Value $<0,05)$ yang berarti Ha diterima

Simpulan : ada pengaruh rendam kaki dengan air hangat terhadap penurunan insomnia pada lansia. Penurunan dari insomnia ringan menjadi tidak insomnia.Diharapkan penelitian ini dapat menjadi terapi yang aman digunakan oleh penderita insomnia terutama pada lansia di panti werda.

Kata kunci : Rendam Kaki, Insomnia, Lansia 


\section{PENDAHULUAN}

Dengan adanya perubahan dan peningkatan pembangunan dalam bidang kesehatan dapat meningkatkan usia harapan hidup sehingga meningkat pula populasi usia lebih dari 60 tahun, dan dengan adanya peningkatan usia harapan hidup dapat mencerminkan bahwa adanya perbaikan kesehatan (Badan Pusat Statistik Republik Indonesia, 2017). Walaupun adanya perbaikan kesehatan, para lansia tersebut akan menghadapi berbagai masalah kesehatan yang khas sepanjang hidupnya (Mariyam, 2008; Departemen Kesehatan Republik Indonesia, 2017; Ximenes, Syafitri \& Amigo, 2016)

Asia Tenggara memiliki 8\% populasi lansia atau sekitar 142 juta jiwa yang menempati urutan pertama di Dunia dengan jumlah lansia terbesar. Di Indonesia memiliki 23.66 juta jiwa (9.03\%) lansia (2017) dengan UHH 70,8 tahun (2015) (Kementrian Kesehatan Republik Indonesia, 2017). Di Lampung tahun 2019 diharapkan penduduk lansia mencpai usia harapan hidup lebih dari 72 tahun (Kementrian Kesehatan Republik Indonesia, 2017; Dinas Kesehatan Provinsi Lampung, 2015).

Lansia merupakan proses penuaan yang terjadi secara alami yang pasti akan terjadi pada setiap makhluk. Pada proses penuaan akan terjadi penurunan, kemunduran dan perubahan fungsi baik fungsi biologis dan fisiologis, psikologis maupun sosial. Lansia sebagian besar beresiko tinggi mengalami gangguan tidur yang disebabkan oleh berbagai factor (Sumirta \& Laraswati,(2014). Proses patologis terkait usia dapat menyebabkan perubahan pola tidur dan mengakibatkan gangguan tidur yang menyerang $50 \%$ orang dengan usia 65 tahun atau lebih. Gangguan tidur mempengaruhi kualitas hidup dan berhubungan dengan angka mortalitas yang tinggi (Irawan, 2013; Dewi, 2015). Sebenarnya gangguan tidur (insomnia) merupakan masalah yang bisa terjadi pada anak-anak, remaja, dewasa, maupun usia lanjut. Kejadian insomnia meningkat seiring meningkatnya usia, sehingga lansia banyak mengalami insomnia, bahkan setengah dari jumlah lansia dilaporkan mengalami kesulitan memulai tidur dan mempertahankan tidur (Dewi, \& Igai, 2014; Mading \&.Muhlisin, 2015) dan insomnia merupakan gangguan tidur yang paling sering ditemukan (Morin, \& Espie, 2007)
Di Dunia yang mengalami insomnia sekitar 18\% dari seluruh penduduk, 1 dari 3 mengalami insomnia. Tiap tahun 20-50\% melaporkan mengalami insomnia. Di Indonesia $10 \%$ atau 28 juta jiwa dari 238 juta jiwa mengalami insomnia Gangguan tidur berhubungan dengan morbiditas (penyakit) dan mortalitas (kematian). Gangguan tidur pada lansia berhubungan dengan resiko jatuh kerena gangguan keseimbangan dikarenakan kesulitan tidur (Sayekti \& Hendrati, 2015; Supriyono, 2015; Sabatini., Kusuma \& Tambunan, 2015; Al-Halaj, 2014).

Dari hasil presurvei di Panti Sosial Tresna Werdha Natar lansia yang tinggal dipanti, dari 10 lansia terdata yang mengalami insomnia sebanyak 4 lansia, yaitu $40 \%$ lansia mengalami insomnia dengan tingkat insomnia ringan dan berat. Rendam kaki dengan air hangat merupakan salah satu metode yang dapat digunakan dalam menurunkan kejadian insomnia pada lansia (Yang., Chen., Lee., Fang \& Chao, 2010; Valizadeh, Seyyedrasooli., Zamanazadeh, \& Nasiri, 2015)

Tujuan untuk mengetahui pengaruh rendam kaki dengan air hangat terhadap penurunan insomnia pada lansia di Panti Sosial Tresna Werdha Natar tahun 2018

\section{METODE PENELITIAN}

Metode penelitian ini adalah rancangan eksperimen semu (quasi eksperiment) dengan pendekatan one group pre post design. penelitian ini dilakukan di Panti Sosial Tresna Werdha Natar Lampung yang dilaksanakan pada bulan maret 2018. Populasi pada penelitian ini adalah 17 orang dengan usia 60-74 tahun yang mengalami insomnia untuk diberikan rendam kaki dengan air hangat. Penelitian ini menggunakan Total Sampling maka seluruh populasi yang ada diberikan tindakan hidroterapi (rendam kaki dengan air hangat).

Pengumpulan data dengan cara wawancara langsung dan menggunakan kuesioner KSPBJ-IRS untuk mengetahui adanya insomnia pada responden. Penelitian ini penggunakan air hangat dengan suhu $37^{0}-39^{\circ} \mathrm{C}$ dan kaki direndam sampai mata kaki (2-3 liter) selama 15-20 menit.Analisa univariat mengukur distribusi frekuensi tindakan rendam kakidan analisa bivariat untuk mengetahui pengaruh tindakan rendam kaki terhadap penurunan insomnia pada lansia di Panti Sosial Tresna Werdha Natar.

Hardono' Program Studi llmu Keperawatan STIKes Aisyah Pringsewu, Lampung. Email: hardonoaisyah2009@gmail.com Elisa Oktaviana ${ }^{2}$ Program Studi Si llmu Keperawatan STIKes Yarsi Mataram, NTB. Email: oktavianaelisa194@gmail.com Andoko $^{3}$ Program Studi llmu Keperawatan, Universitas Malahayati, Bandar Lampung. Email: andoko2013@gmail.com 
HASIL

Tabel 1. Distribusi frekuensi jenis kelamin lansia yang diberikan rendam kaki dengan air hangat $(\mathrm{N}=17)$

\begin{tabular}{ccc}
\hline Jenis kelamin & Frekuensi & $\%$ \\
\hline Laki-laki & 8 & 47 \\
Perempuan & 9 & 53 \\
Total & 17 & 100 \\
\hline
\end{tabular}

Berdasarkan Tabel 1 hasil penelitian didapat data 17 responden dengan jumlah laki-laki 8 (47\%) dan jumlah perempuan 9 (53\%).

Tabel 2. Distribusi frekuensi usia lansia yang diberikan rendam kaki dengan air hangat $(\mathrm{N}=17)$

\begin{tabular}{ccc}
\hline Usia (tahun) & Frekuensi & $\%$ \\
\hline $60-65$ & 1 & 5.9 \\
$66-70$ & 5 & 29.4 \\
$71-75$ & 11 & 64.7 \\
Total & 17 & 100 \\
\hline
\end{tabular}

Berdasarkan Tabel 2 dengan usia yang ada mulai dari 65 tahun sampai 74 tahun. Usia 60-65 tahun terdapat 1 (5.9\%), usia 66-70 tahun terdapat $5(29.4 \%)$, dan usia $71-75$ tahun terdapat $11(64.7 \%)$

Tabel 3. Uji Normalitas Data

\begin{tabular}{ccc}
\hline \multicolumn{3}{c}{ Shapiro-Wilk } \\
\hline Statistik & df & Sig. \\
\hline 0.927 & 17 & 0.195 \\
\hline
\end{tabular}

Berdasarkan tabel 3 didapatkan data signifikan 0.195 yang merupakan $>0.005$ yang berarti berdistribusi normal sehingga menggunakan uji $t$, dan karena jumlah responden kurang dari 50 sehingga menggunakan Shapiro-Wilk.

Tabel 4. Rerata Skor Insomnia Sebelum Diberikan Rendam Kaki dengan air hangat $(\mathrm{N}=17)$

\begin{tabular}{lccccc}
\hline & Mean & Sd & Min & Max & Std Error Mean \\
& & & & & \\
\hline Pre & 25.76 & 4.493 & 20 & 32 & 1.090 \\
Post & 17.18 & 2.963 & 13 & 22 & 0.719 \\
\hline
\end{tabular}

Berdasarkan tabel 4 diketahui bahwa rerata skor insomnia sebelum diberikan rendam kaki dengan air hangat dari 17 responden yaitu 25,76 yang berarti rata-rata lansia mengalami insomnia ringan. Nilai skor insomnia tertinggi 32 dan nilai terendah skor insomnia 20. Nilai standar deviasi 4.493 dan standar error mean 1.090.

Hardono' Program Studi llmu Keperawatan STIKes Aisyah Pringsewu, Lampung. Email: hardonoaisyah2009@gmail.com Elisa Oktaviana ${ }^{2}$ Program Studi Si llmu Keperawatan STIKes Yarsi Mataram, NTB. Email: oktavianaelisa194@gmail.com Andoko $^{3}$ Program Studi llmu Keperawatan, Universitas Malahayati, Bandar Lampung. Email: andoko2013@gmail.com 
RENDAM KAKI DENGAN AIR HANGAT SALAH SATU TERAPI YANG MAMPU MENGATASI INSOMNIA PADA LANSIA

Berdasarkan hasil data diketahui bahwa rerata skor insomnia setelah diberikan rendam kaki dengan air hangat dari 17 Lansia atau responden yaitu 17,18 yang berarti rata-rata Lansia sudah tidak mengalami insomnia. Nilai skor insomnia tertinggi 22 dan nilai terendah skor insomnia 13.

Tabel 5. Pengaruh rendam kaki dengan air hangat terhadap penurunan skor insomnia $(\mathrm{N}=17)$

Paired Difference

\begin{tabular}{|c|c|c|c|c|c|c|c|c|}
\hline & \multirow[t]{2}{*}{ Mean } & \multirow{2}{*}{$\begin{array}{c}\text { Std } \\
\text { Deviation }\end{array}$} & \multirow{2}{*}{$\begin{array}{l}\text { Std Error } \\
\text { Mean }\end{array}$} & \multicolumn{2}{|c|}{$\begin{array}{c}95 \% \text { convidence interval } \\
\text { of the Difference }\end{array}$} & \multirow[t]{2}{*}{$t$} & \multirow[t]{2}{*}{ df } & \multirow[t]{2}{*}{ Sig. (2-taile) } \\
\hline & & & & Lower & Upper & & & \\
\hline Pair 1 Pre-Post & 8.588 & 2.694 & 0.653 & 7.703 & 9.973 & 13.144 & 16 & 0.000 \\
\hline
\end{tabular}

Berdasarkan tabel 5 dapat dilihat hasil uji t statistik diperoleh nilai signifancy $=0,000$ (P-Value $<0,05$ ) yang berarti Ha diterima sehingga ada pengaruh rendam kaki dengan air hangat terhadap penurunan insomnia pada lansia di Panti Sosial Tresna Werdha Natar.

\section{PEMBAHASAN}

Rerata Skor Insomnia sebelum dan sesudah diberikan rendam kaki dengan air hangat

Hasil penelitian didapat data sebelum rendam kaki rerata skor insomnia 25.76 (insomnia ringan), nilai skor terendah 20 (insomnia ringan) dan nilai skor tertinggi 32 (insomnia berat).11 responden mengalami insomnia ringan dan 6 responden mengalami insomnia berat. Hasil penelitian didapat data setelah rendam kaki dengan air hangat selama 5 hari rerata skor 17.18 (tidak insomnia), nilai skor terendah 13 (tidak insomnia) dan nilai skor tertinggi 22 (insomnia ringan). Terjadinya penurunan skor insomnia tersebut dikarena efek hangat yang ditimbulkan saat rendam kaki yang menyebabkan rasa nyaman, rileks sehingga memudahkan dalam dan hidroterapi adalah teknik untuk menghilangkan rasa sakit dan mengobati penyakit yang memberikan efek teraupetik menyebabkan rileks pada otot mempengaruhi system limbik sehingga merasa nyaman (Permady, 2015; Apriliani, 2018). Hidroterapi memberikan efek fisiologis pada tubuh berupa rileks, hidroterapi menyalurkan rasa hangat melalui kulit pada kaki yang memiliki syaraf fleksusfenosus, dari saraf inilah stimulasi diteruskan ke kornus posterior kemudian dilanjutkan ke medulla spinalis lalu ke radiks dorsalis selanjutnya ke ventro basal thalamus yang mempengaruhi hipotalamus memproduksi hormone melatonin dan kemudian otak merespon dengan timbulnya efek sofartifik (rasa ingin tidur)
(Dionesia, 2017; Prananto, 2016; Utami \& Suratini, 2015; Permady, 2015).

Berdasarkan hasil penelitian yang didapat disimpulkan bahwa dari 17 responden sebelum dan sesudah terjadi penurunan skor insomnia dari rerata skor 25.76 menjadi rerata skor 17.18 yang terjadi penurunan sebanyak 8.588 yaitu dari insomnia ringan menjadi tidak insomnia, tetapi ada 4 dari 17 responden yang saat pre-test mengalami insomnia berat dan saat post-test masih mengalami insomnia ringan. Adapun 4 responden lainnya yang masih mengalami insomnia walaupun sudah terjadi penurunan skor insomnia dari insomnia berat menjadi insomnia ringan, hal ini di karenakan skor sebelumnya yang terlalu tinggi yaitu dengan skor 32 sehingga hanya mampu turun diderajad insomnia ringan.Sedangkan 13 responden lainnya setelah dilakukan rendam kaki sudah tidak insomnia.

\section{Pengaruh rendam kaki dengan air hangat terhadap penurunan skor insomnia}

Hasil penelitian menunjukan bahwa skor rerata insomnia sebelum diberikan rendam kaki adalah 25.76 yang artinya rata-rata insomnia ringan, dari 17 responden mengalami insomnia ringan dan berat. Skor insomnia tertinggi saat sebelum perlakuan rendam kaki adalah 32 (insomnia berat) dan setelah diberikan rendam kaki skor insomnia terendah menjadi 20 (insomnia ringan). Skor rerata insomnia setelah diberikan rendam kaki adalah 17.18 (tidak

Hardono' Program Studi llmu Keperawatan STIKes Aisyah Pringsewu, Lampung. Email: hardonoaisyah2009@gmail.com Elisa Oktaviana ${ }^{2}$ Program Studi SI llmu Keperawatan STIKes Yarsi Mataram, NTB. Email: oktavianaelisa194@gmail.com Andoko ${ }^{3}$ Program Studi llmu Keperawatan, Universitas Malahayati, Bandar Lampung. Email: andoko2013@gmail.com 
insomnia) dan dari 17 responden 13 diantaranya sudah tidak insomnia dan 4 responden dengan insomnia ringan. Setelah diberikan rendam kaki skor insomnia tertinggi adalah 22 (insomnia ringan) dan skor insomnia terendah adalah 13 (tidak insomnia).

Berdasarkan dari hasil uji statistik menggunakan uji paired $t$ test diperoleh $p$ value $0.000(p<0.05)$ artinya $\mathrm{Ha}$ diterima sehingga dapat disimpulkan bahwa ada pengaruh rendam kaki dengan air hangat terhadap penurunan insomnia pada lansia di Panti Sosial Tresna Werdha Natar. Jika dilihat dari nilai rerata skor insomnia sebelum diberikan rendam kaki dan setelah diberikan rendam kaki terjadi perubahan dari 25.76 (insomnia ringan) menjadi 17.18 (tidak insomnia) yang mengalami penurunan sebanyak 8.588.Jadi pada penelitian ini ada penurunan skor insomnia pada lansia sebelum dan sesudah diberikan rendam kaki dengan air hangat.

Penggunaan air hangat untuk pengobatan dalam hidroterapi ini adalah efek hidrostastik dan hidrodinamik .Secara ilmiah air hangat memberikan dampak fisiologis pada tubuh, pada pembuluh darah hangatnya air mampu melancarkan sirkulasi darah.Saat dalam air terjadi pertukaran energi atau panas melalui mekanisme konduksi, konveksi, radiasi, dan evaporasi.Air adalah media penyerap, penghasil panas yang mempunyai efek teraupetik. Relaksasi otot yang didapat mampu menigkatkan kelenturan pada jaringan dan mempengaruhi system limbik sehingga kita merasa nyaman dan stress emosional hilang. Dengan pencelupan anggota tubuh kedalam air akan mengembalikan tubuh yang lemah menjadi kuat, mengurangi kekejangan pada syaraf dan otot, menormalkan detak jantung, kecemasan dan insomnia (Rinawati, \& Isnaeni, 2012; Darmadi, 2017; Putra, 2018).

Berdasarkan hasil penelitian yang didapat bahwa terjadi penurnan rerata skor insomnia yang awalnya 25.76 yang merupakan insomnia ringan menjadi rerata skor insomnia 17.18 yang merupakan tidak insomnia dengan nilai penurunan sebanyak 8.588 . Terjadi penurunan skor tertinggi dari 32 yang merupakan insomnia berat menjadi 22 yang merupakan insomnia ringan, dan penurunan skor terendah dari 20 yang merupakan insomnia ringan menjadi skor 13 (tidak insomnia) (Lendengtariang, Wungouw \& Hamel, 2018; Khotimah, 2012; Dionesia, 2017).
Berdasarkan hasil penelitian Insomnia terutama banyak terjadi pada perempuan karena perubahan hormon yang menyebabkan penurunan hormon melatonin sebagai pengatur tidur bangunya manusia. Namun tidak menjadikan bahwa laki-laki tidak mengalami insomnia karena laki-laki kurang mampu mengekspresikan perasaannya yang menyebabkan laki-laki mengalami tekanan psikologisnya dan juga banyak laki-laki memiliki gaya hidup yang buruk.

Berdasarkan hasil penelitian dan berdasarkan jurnal yang ada disimpulkan dengan meningkatnya kualitas tidur dan terpenuhinya kebutuhan tidur mampu menurunkan rasa ketidaknyamanan, membuatnya lebih merasa rileks yang akan meregangkan syaraf-syaraf yang kaku sehinggan gejala insomnia pun berkurang. Terjadinya penurunan insomnia pada lansia ini terjadi karena air hangat yang mampu menyalurkan rasa rileks dan nyaman dan mampu menstimulus otak untuk memerintahkan hipotalamus untuk meningkatkan produksi hormon melatonin yang memiliki turunan hormon serotonin sebagai pengatur pola tidur manusia dan gelombang sikardian manusia. Selain itu personal hygiene pada responden, temat tidur yang bersih dan nyaman, lingkungan yang bersih dan nyaman juga berperan dalam meningkatkan kenyamanan responden (lansia) dipanti saat tidur sehingga mampu meningkatkan kualitas tidur dan menurunkan insomnia.

\section{SIMPULAN}

Dari penelitian ini dapat disimpulkan bahwa Rerata skor insomnia sebelum diberikan rendam kaki dengan air hangat dari 17 responden (lansia) yaitu 25,76 yang berarti rata-rata Lansia mengalami insomnia ringan dengan nilai skor insomnia tertinggi 32 (insomnia berat) dan nilai terendah skor insomnia 20 (insomnia ringan).

Rerata skor insomnia setelah diberikan rendam kaki dengan air hangat dari 17 Lansia atau responden yaitu 17,18 yang berarti rata-rata Lansia sudah tidak mengalami insomnia. Nilai skor insomnia tertinggi 22 (insomnia ringan) dan nilai terendah skor insomnia 13 (tidak insomnia).

Nilai $p$ value $0.000<0.005$ jadi Ha diterima sehingga ada pengaruh rendam kaki dengan air hangat terhadap penurunan insomnia pada lansia. nilai rerata skor insomnia sebelumnya 25.76

Hardono' Program Studi llmu Keperawatan STIKes Aisyah Pringsewu, Lampung. Email: hardonoaisyah2009@gmail.com Elisa Oktaviana ${ }^{2}$ Program Studi SI llmu Keperawatan STIKes Yarsi Mataram, NTB. Email: oktavianaelisa194@gmail.com Andoko ${ }^{3}$ Program Studi llmu Keperawatan, Universitas Malahayati, Bandar Lampung. Email: andoko2013@gmail.com 
RENDAM KAKI DENGAN AIR HANGAT SALAH SATU TERAPI YANG MAMPU MENGATASI INSOMNIA PADA LANSIA

(insomnia ringan) dan sesudahnya 17.18 (tidak insomnia) yang mengalami penurunan sebanyak 8.588. Jadi pada penelitian ini ada penurunan skor insomnia pada lansia sebelum dan sesudah diberikan rendam kaki dengan air hangat.

\section{DAFTAR PUSTAKA}

Al-Halaj, Q. M. I. (2014). Pengaruh Dzikir Menjelang Tidur Terhadap Kualitas Tidur Lanjut Usia di Panti Sosial Tresna Wredha Budi Mulia 01 Jakarta Timur.

Apriliani, A. L. (2018). Efektifitas terapi murottal dan hidroterapi rendam kaki air hangat terhadap tekanan darah pada pasien hipertensi di kelurahan Srondol Kulon (Doctoral dissertation, Universitas Muhammadiyah Semarang).

Badan Pusat Statistik Republik Indonesia (2017). Indeks Pembangunan Manusia 2016. Jakarta (ID): Badan Pusat Statistik.

Darmadi, H. (2017). Hidup sehat dengan terapi air wudhu: Diandra Kreatif. Diandra Kreatif.

Departemen Kesehatan Republik Indonesia. (2017). Analisis Lansia di Indonesia di akses file://C:/Users/user/Downloads/Analisis\%20Lansi a\%20Indonesia\%202017\%20(1).pdf

Dewi, P. A., \& Igai, A. (2014). Angka kejadian serta faktor-faktor yang mempengaruhi gangguan tidur (insomnia) pada lansia di Panti Sosial Tresna Werda Wana Seraya Denpasar Bali Tahun 2013. EJ Medika Udayana, 3(10), 1-13.

Dewi, S. R.(2015). Buku ajar keperawatan gerontik. Deepublish.

Dinas Kesehatan Provinsi Lampung (2015). Renstra. Diakses

file:///C:/Users/user/Downloads/RENSTRA.pdf
Dionesia, E. A. (2017). Perbedaan efektifitas tindakan massage dan pemberian rendam air hangat dalam memenuhi kualitas tidur pada lansia. Jurnal Riset Kesehatan Nasional, 1(2), $111-118$.

Irawan, H. (2013). Gangguan depresi pada lanjut usia. Cermin Dunia Kedokteran, 40(11), 815-819. Irawan, H. (2013). Gangguan depresi pada lanjut usia. Cermin Dunia Kedokteran, 40(11), 815-819.

Kementrian Kesehatan Republik Indonesia. (2017) diakses

file:///C:/Users/user/Downloads/Analisis\%20Lansi a\%20Indonesia\%202017\%20(5).pdf

Khotimah, K. (2012). Pengaruh Rendam Air Hangat pada Kaki dalam Meningkatan Kuantitas Tidur Lansia. In Seminar Nasional Competitive Advantage 2012. Universitas Pesantren Tinggi Darul'Ulum.

Lendengtariang, C., Wungouw, H., \& Hamel, R. S. (2018). Pengaruh terapi rendam air hangat pada kaki terhadap insomnia pada lansia di kelurahan Angges Kecamatan Tahuna Barat. Jurnal keperawatan, 6(2).

Mading, M. F. \& Muhlisin, H. A. (2015). Gambaran karakteristik lanjut usia yang mengalami insomnia di Panti Wreda Dharma Bakti Pajang Surakarta (Doctoral dissertation, Universitas Muhammadiyah Surakarta

Maryam, S. (2008). Menengenal Usia Lanjut dan Perawatannya. Penerbit Salemba.

Permady, G. G. (2015). Pengaruh merendam kaki dengan air hangat terhadap kualitas tidur lansia di wilayah kerja Puskesmas Astanalanggar kecamatan Losari Cirebon Jawa Barat.

Prananto, A. E. (2016). Pengaruh Masase Kaki Dan Rendam Air Hangat Pada Kaki Terhadap Penurunan Insomnia Pada Lansia (Doctoral dissertation, Universitas Muhammadiyah Surakarta

Hardono' Program Studi llmu Keperawatan STIKes Aisyah Pringsewu, Lampung. Email: hardonoaisyah2009@gmail.com Elisa Oktaviana ${ }^{2}$ Program Studi S1 llmu Keperawatan STIKes Yarsi Mataram, NTB. Email: oktavianaelisa194@gmail.com Andoko ${ }^{3}$ Program Studi llmu Keperawatan, Universitas Malahayati, Bandar Lampung. Email: andoko2013@gmail.com 
RENDAM KAKI DENGAN AIR HANGAT SALAH SATU TERAPI YANG MAMPU MENGATASI INSOMNIA PADA LANSIA

Putra, Y. A. E. (2018). Pengaruh hidroterapi kaki terhadap penurunan skor insomnia pada lanjut usia di Panti Werdha Muhammadiyah Kota Probolinggo. The Indonesian Journal of Health Science, 1-6.

Rinawati, M., \& Isnaeni, Y. (2012). Pengaruh Terapi Wudhu Sebelum Tidur terhadap Kejadian Insomnia pada Usia Lanjut di Dusun Tilaman Wukirsari Imogiri Bantul Yogyakarta (Doctoral dissertation, STIKes'Aisyiyah Yogyakarta).

Sabatini, S. N., Kusuma, H. E., \& Tambunan, L. (2015). Faktor eksternal risiko jatuh lansia: studi empiris. Prosiding Temu IImiah IPLBI, 30-31.

Sayekti, N., \& Hendrati, L. (2015). Analisis risiko depresi, tingkat sleep hygiene dan penyakit kronis dengan kejadian insomnia pada lansia. Jurnal FKM, 3(2).

Sumirta, I. N., \& Laraswati, A. I. (2014). Faktor yang menyebabkan gangguan tidur (insomnia) pada lansia. Jurnal Keperawatan Politeknik Kesehatan Denpasar.
Utami, T., \& Suratini, S. (2015). Pengaruh Rendam Air Hangat pada Kaki Terhadap Insomnia pada Lansia di Panti Sosial Tresna Werdha Yogyakarta Unit Budi Luhur (Doctoral dissertation, STIKES'Aisyiyah Yogyakarta).

Valizadeh, L., Seyyedrasooli, A., Zamanazadeh, V., \& Nasiri, K. (2015). Comparing the effects of reflexology and footbath on sleep quality in the elderly: a controlled clinical trial. Iranian Red Crescent Medical Journal, 17(11).

Ximenes, P. L., Syafitri, E. N., \& Amigo, T. A. E. (2016). Pengaruh terapi musik terhadap kualitas tidur pada lansi di bpstw yogyakarta unit abiyoso. Jurnal Keperawatan Respati Yogyakarta, 3(2), 35-38.

Yang, H. L., Chen, X. P., Lee, K. C., Fang, F. F., \& Chao, Y. F. (2010). The effects of warm-water footbath on relieving fatigue and insomnia of the gynecologic cancer patients on chemotherapy. Cancer nursing, 33(6), 454-460.

Hardono' Program Studi llmu Keperawatan STIKes Aisyah Pringsewu, Lampung. Email: hardonoaisyah2009@gmail.com Elisa Oktaviana ${ }^{2}$ Program Studi SI llmu Keperawatan STIKes Yarsi Mataram, NTB. Email: oktavianaelisa194@gmail.com Andoko ${ }^{3}$ Program Studi llmu Keperawatan, Universitas Malahayati, Bandar Lampung. Email: andoko2013@gmail.com 